\title{
Drawing Down Retirement Financial Savings: A Welfare Analysis using French data
}

\author{
Najat El Mekkaoui \\ Université Paris-Dauphine PSL, najat.el-mekkaoui@dauphine.psl.eu
}

Jorge, M. Bravo

NOVA IMS - Universidade Nova de Lisboa \& Université Paris-Dauphine PSL \& CEFAGE-UE, jbravo@novaims.unl.pt

This is the author accepted manuscript version of the paper published by ACM as:

Bravo, J. M., \& Freitas, N. E. M. D. (2021). Drawing Down Retirement Financial Savings: A Welfare Analysis using French data. In 2021 The 5th International Conference on E-Commerce, E-Business and E-Government (ICEEG '21) (pp. 152-158). Association for Computing Machinery (ACM). https://doi.org/10.1145/3466029.3466041 


\title{
Drawing Down Retirement Financial Savings: A Welfare Analysis using French data
}

\author{
Drawing Down Retirement Financial Savings
}

Najat, El Mekkaoui

Université Paris-Dauphine PSL, najat.el-mekkaoui@dauphine.psl.eu

Jorge, M. Bravo*

NOVA IMS - Universidade Nova de Lisboa \& Université Paris-Dauphine PSL \& CEFAGE-UE, jbravo@novaims.unl.pt

In recent decades, most countries have responded to increased longevity, population ageing, and low market returns with systemic and/or gradual parametric pension reforms. The trend towards individual accounts in public and private funded pension schemes augmented the importance of studying the decumulation phase of pensions. This paper uses a simulation design to empirically investigate the individual welfare generated from alternative annuitization and self-managed fixed, variable and hybrid drawdown strategies. A time-separable utility function is used to represent an individual's preferences towards consumption and bequest, risk aversion, and intertemporal discounting and to quantitively assess the range of retirement outcomes from competing decumulation designs. The setting comprises a stochastic mortality and investment risk framework calibrated to French interest rate, stock market, and mortality data from 2010 to 2019. The results show that self-managed variable decumulation strategies may generate higher income at the expense of high risk-taking, more volatile income streams, and no longevity insurance. Annuitization strategies involving longevity-linked life annuities and hybrid solutions provide higher expected lifetime utility at the expense of bequest motives.

CCS CONCEPTS • Modeling and simulation • Continuous mathematics • Law, social and behavioral sciences

Keywords: Drawdown strategies, pensions, longevity-linked life annuity, longevity insurance, retirement savings.

\section{INTRODUCTION}

In recent decades, most countries have responded to continuous longevity improvements, population ageing, and low market returns with systemic and/or gradual parametric pension reforms to restore solvency and enhance the fiscal sustainability of public pensions while balancing with pension adequacy concerns. Adopted reforms include modifying the pension system rules and parameters (e.g., the retirement age), increasing pre-funding (reserve funds), enhancing work incentives, modifying pension taxation, expanding contribution options, expanding the coverage of private funded (mandatory or voluntary) pensions, developing auto-enrolment schemes, switching from existing DB schemes to DC schemes, expanding individual accounts in personal, employer, and state pensions and providing greater freedom over how pension pots $[1-3,27]$. The growth of financial and notional individual account systems and longevity developments have increased the importance of studying the decumulation phase of pensions from different perspectives. The retirement savings drawdown choice has traditionally been grouped into three payout options: (i) The purchase of a fixed or escalating life annuity, where the retiree converts his or her full DC financial wealth into a guaranteed income stream; (ii) providing a lump-sum benefit or a lump-sum option at retirement, followed by a self-managed retirement wealth strategy; (iii) Hybrid approaches combining annuitization (considering for innovative longevity-linked and with-profit annuities $[5,16,28,36]$ ) and discretionary wealth management. In most cases, housing wealth is ignored.

\footnotetext{
* Corresponding author: Universidade Nova de Lisboa - NOVA IMS, Campus de Campolide, 1070-312 Lisbon-Portugal; jbravo@novaims.unl.pt.
} 
Contrary to the standard Modigliani life-cycle model, in most countries voluntary annuitization is limited and decreasing and the actual saving/dissaving behaviour is often at odds with economic theory, with several demandside and supply-side arguments explaining this "annuity puzzle. The timing and strategy adopted to decumulate financial and non-financial wealth are one of the most important decisions individuals make as they approach and enter retirement. The decumulation process may resume to a single decision made at the time of retirement (e.g., using the entire wealth to buy a life annuity), or a sequence of ad-hoc or programmed and rational decisions spanned throughout the whole retirement period (e.g., following some drawdown rule). The decumulation strategy may include longevity, investment, inflation, health care, and other risk guarantees, and often requires individuals to decide upon how much to consume from the pension pot to live on, to foresee their remaining lifetime, to rebalance the asset mix during retirement [7]. The alternative decumulation strategies often target to minimize longevity and investment risks while optimizing over some objective function (e.g., keep up with inflation, minimize income volatility and wealth depletion, maximize consumption, leave a bequest). The search for the "right" decumulation strategy must consider both individual circumstances and preferences (e.g., initial wealth level and composition, preferences over consumption and bequest, behavioral biases, the role of unexpected shocks that may alter decumulation - the death of a partner, divorce, health shocks, long term care -, the existence of other sources of guaranteed income), and the enabling environment (e.g., financial market development, pensions taxation, incomplete annuity markets, government benefits) [8-11]. Simple fixed or variable self-managed drawdown rules such as splitting the retirement wealth into equal portions based on the remaining lifetime at retirement age are often derived from rules of thumb, subjective judgments, and bounded rationality assumptions. More sound approaches employ a utility function (or cumulative prospect theory) to represent an individual's preferences and use dynamic programming or stochastic simulation to solve for the optimal decumulation path, the timing and amount of the annuitization decision, the appropriate investment strategy, the probability of lifetime ruin. The control variables are typically the consumption rate and the asset mix. Empirical evidence shows there is a breach between the behavior implied by lifecycle economic models and that of real-world individual decumulation decisions. The average individual (and most financial advisors) have limited financial literacy and hardly would be able to master the skills required to solve for the optional drawdown path.

This paper uses a simulation design to empirically investigate the individual welfare generated from alternative drawdown strategies. The set of strategies tested comprise annuitization and self-managed fixed, variable and hybrid drawdown approaches, simple decision rule methods, actuarial methods, and innovative annuity contract structures. To quantitatively assess the retirement outcomes of competing decumulation designs, we use a timeseparable utility function accounting for the preference towards consumption and bequest, risk aversion, and intertemporal discounting. We use Monte Carlo simulation methods and a stochastic mortality and investment risk framework to model biometric and financial market risks. The dynamics of mortality rates are modelled using Generalized Age-Period-Cohort (GAPC) stochastic mortality models [12]. The market price of longevity risk is incorporated using a risk-neutral simulation approach. The stochastic dynamics of bond prices are determined based on a two-factor equilibrium model [13]. We assume stock prices follow a geometric Brownian motion. The models are calibrated to financial market and mortality data for France. The expected lifetime utility is computed as the average lifetime utility across the bi-dimensional (investment performance and survival prospects) simulation paths. The results show that self-managed variable decumulation strategies may generate higher income at the expense of high risk-taking, more volatile income streams, and no longevity insurance. Annuitization strategies involving longevity-linked life annuities and hybrid solutions provide higher expected lifetime utility at 
the expense of bequest motives. The remainder of the paper is as follows. Section 2 outlines the key concepts and research methods used in the paper. Section 3 reports and discusses the pricing and simulation results. Section 4 concludes.

\section{MATERIALS AND METHODS}

\subsection{Welfare analysis of drawdown strategies}

This paper quantitatively investigates the individual welfare generated from eight alternative drawdown strategies: (i) a self-managed fixed drawdown rule based on cohort life expectancy estimated at contract inception, i.e., age $x_{0}$ and year $t_{0}\left[1 / e_{x_{0}, t_{0}}\right.$ rule]; (ii) a self-managed non-insurance fixed drawdown rule based on the life annuity factor computed at contract initiation $\left[1 / a_{x_{0}, t_{0}}\right.$ rule]; (iii) a self-managed variable drawdown rule based on a dynamic assessment of the remaining cohort life expectancy estimated at age $x_{0}+k$ in year $t_{0}+k\left[1 / e_{x_{0}+k, t_{0}+k}\right.$ rule], $k=$ $0,1, \ldots, \omega-x_{0}$, where $\omega$ is the highest attainable age; (iv) The classical "4\%" SWR rule, where households consume each year $4 \%$ of the initial wealth adjusted for observed CPI inflation [14-15]; (v) An annuitization strategy using entire financial savings to buy a participating longevity-linked life annuity (PLLA), an innovative risk-sharing life insurance contract in which payments are periodically updated according to both the observed survival experience of a reference pool against the expected survival path and the investment performance of the financial assets backing the contract against the guaranteed interest rate [16].1 Formally, PLLA annuity benefits at time $t_{0}+k$, $b_{t_{0}+k}$, depart from their initial value $b_{t_{0}}$ depending on the dynamics of both a longevity adjustment factor $\mathrm{I}_{t_{0}+k}$ and an interest rate adjustment (IRA) $R_{t_{0}+k}$ factor:

$$
b_{t_{0}+k}=b_{t_{0}} \times \mathrm{I}_{t_{0}+k} \times R_{t_{0}+k}, \quad k=1, \ldots, \omega-x,
$$

where $\mathrm{I}_{t_{0}+k}$ is defined as the ratio between the expected and the observed survival probability in a reference population, $\mathrm{I}_{t_{0}+k}={ }_{k} p_{x_{0}}^{\left[F_{0}\right]}\left(t_{0}\right) /{ }_{k} p_{x_{0}}^{\left[F_{k}\right]}\left(t_{k}\right)$, with ${ }_{k} p_{x_{0}}\left(t_{0}\right)$ denoting the $k$-year survival probability of some reference population cohort aged $x_{0}$ at time $t_{0}$, and $R_{t_{0}+k}$ is defined by $R_{t_{0}+k}=\prod_{j=0}^{k-1}\left(1+R_{t}\right) /(1+y)^{k}$, where $R_{t}$ is the net investment return observed in year $t$ and $y$ is the guaranteed interest rate, set at zero percent in this study. Benefit volatility is limited at 20\%; (vi) purchasing a fixed single premium nominal life annuity (SPLA) at retirement age; (vii) A hybrid strategy allocating 70\% of the retirement wealth to the "4\%" SWR rule and the remaining 30\% to an advanced life deferred annuity (ALDA) with a 15-year deferment period; (viii) Purchasing an Inflation-Protected Annuity (IPA) at retirement.

The minimum annual consumption level is set at $6000 €$ per year in all strategies. We consider a 30-year investment horizon. Policyholders evaluate risks and guarantees based on individual risk preferences. To represent individual preferences, we consider a time-separable utility function including lifetime consumption and bequest motives and assume individuals maximize the expected present value of utility derived from consumption [18],

$$
U_{t}=\max _{c_{1}, c_{2}, \ldots, c_{T}} E_{t}\left[\sum_{k=1}^{\omega-x_{0}} \beta^{k}\left\{{ }_{k} p_{x_{0}}^{\left[F_{0}\right]} u\left(c_{t}\right)+{ }_{k-1} q_{x_{0}}^{\left[F_{0}\right]} \gamma\left(W_{t}\right)\right\}\right]
$$

where $\beta$ is the subjective discount factor, $u\left(c_{t}\right)$ is a constant relative risk aversion (CRRA) utility function, i.e., $u\left(c_{t}\right)=\frac{c_{t}^{1-\rho}}{1-\rho}, c_{t} \geq 0$, with $\rho>0$ the level of risk aversion, and

\footnotetext{
${ }^{1}$ See $[21,23]$ for alternative non-insurance risk sharing annuity structures.
} 


$$
\left(W_{t}\right)=\left(\frac{\varphi}{1-\varphi}\right)^{\rho} \frac{\left(\frac{\varphi}{1-\varphi} c_{b}+W_{t}\right)^{1-\rho}}{1-\rho}, \quad W_{t} \geq 0
$$

where $c_{b}$ measures the degree to which bequests are considered as luxury goods, and $\varphi[0,1)$ measures the strength of the member's bequest motive when bequest has kicked in (i.e., when $W_{t}>c_{b}$ ). The utility function separately considers the risk aversion over consumption and bequest, allowing for subjective adjustments to how the individuals value different retirement outcomes. The utility function assigns higher values on favorable (higher) income and consumption streams (not lump sums) and bequest outcomes while marking down poor scenarios. Income (consumption) volatility and wealth depletion (ruin) scenarios are considered undesirable strategy outcomes, but the existence of residual assets at death is positively assessed. Individuals are considered risk-averse, i.e., they value asymmetrically adverse and positive outcomes. The dynamics of wealth is as follows:

$$
W_{t+1}=\left(W_{t}-c_{t}+P_{t}\right)\left(1+R_{t+1}\right),
$$

where $R_{t+1}$ is the stochastic (post-tax) rate of return and $P_{t}$ is, e.g., some government pension benefit, assumed zero in this study. The expected utility (2) can be converted into other measures (scores) to enhance its interpretability and to allow a straighter comparison of the welfare-enhancing characteristics of alternative drawdown strategies. To this end, we follow [18] and compute a utility score, $S_{0}$, defined as the constant level of income which delivers a utility level equivalent to that provided by each strategy,

$$
S_{0}=\left[U_{0} \times \frac{1-\rho}{\left(\sum_{k=1}^{\omega-x_{0}} \beta^{k}\left\{{ }_{k} p_{x_{0}}^{\left[F_{0}\right]}+{ }_{k-1} q_{x_{0}}^{\left[F_{0}\right]}\left(\frac{\varphi}{1-\varphi}\right)\right\}\right)}\right]^{\frac{1}{1-\rho}} .
$$

The higher the utility score, the more welfare-enhancing the drawdown strategy is. Additionally, we compute the constant level of income which delivers an equivalent level of income utility $S_{\mathrm{c}}=\left[U_{0}(1-\rho)\left(\sum_{k=1}^{\omega-x_{0}} \beta^{k}{ }_{k} p_{x_{0}}^{\left[F_{0}\right]}\right)\right]^{\frac{1}{1-\rho}}$, the consumption level in the one-period CRRA utility function that matches the lifetime utility, $C E C_{0}$, defined as $C E C_{0}=\left[U_{\mathrm{C}} \times(1-\rho)\right]^{\frac{1}{1-\rho}}$, and a welfare gap measure $G_{0}$, defined as the initial wealth difference between alternative decumulation solutions required to produce equivalent expected utility:

$$
G_{0}=\left(S_{0}-S_{0}^{*}\right)\left(\sum_{k=1}^{\omega-x_{0}} \beta^{k}\left[{ }_{k} p_{x_{0}}^{\left[F_{0}\right]}+{ }_{k-1} q_{x_{0}}^{\left[F_{0}\right]}\left(\frac{\varphi}{1-\varphi}\right)\right]\right)
$$

where $S_{0}^{*}$ is the benchmark utility score. Table 1 summarizes the key design parameters used in this study.

Table 1: Baseline simulation design parameters

\begin{tabular}{lcc}
\hline \multicolumn{1}{c}{ Parameter } & Value & Notes \\
\hline Subjective utility discount factor: $\beta$ & 0.975 & \\
Risk aversion coefficient: $\rho$ & 5 & \\
Strength of bequest motive: $\varphi$ & 0.83 & \\
Bequests as luxury goods level: $c_{b}$ & 25.8 & $\times 10^{3}$ EUR \\
Initial wealth (1000s): $W_{0}$ & 175.2028 & $\times 10^{3}$ EUR \\
Tax rate: $s$ & $20 \%$ & \\
ALDA Deferment period: $k$ & 15 & years \\
Life annuity loading factor & $5 \%$ & \\
Investment horizon & 30 & years \\
\hline
\end{tabular}

Source: Author's elaboration. Note: Initial wealth set at the average retirement savings in France in 2019. 


\subsection{Financial markets}

We assume individuals and the life insurance (annuity) provider invest their retirement savings or insurance premium (in the case of annuitization strategies) in a fixed allocation portfolio comprising risk-free coupon bonds (70\%) and dividend-paying stocks (30\%). Regular bond coupon and dividend payments are invested in a riskless short-term bank account until the next (annual) portfolio rebalancing [20,29]. The valuation framework comprises a risk-neutral, frictionless, and continuous financial market. To model yield curve dynamics, we use a two-factor equilibrium Vasicek model [13] assuming that $r_{t}$ is a sum of two independent Ornstein-Uhlenbeck processes $x_{t}$ and $y_{t}$ (usually modelled as the short-term rate and the long-term rate)

$$
\begin{gathered}
r_{t}=x_{t}+y_{t} \\
x_{t}=\beta_{x}\left(\mu_{x}-x_{t}\right) d t+\sigma_{x} d W_{1}(t) \\
y_{t}=\beta_{y}\left(\mu_{y}-y_{t}\right) d t+\sigma_{y} d W_{2}(t) .
\end{gathered}
$$

where $r_{0}=x_{0}+y_{0}, x(0)=x_{0}, y(0)=y_{0}$, and $\left(W_{1}, W_{2}\right)$ is a two-dimensional Brownian motion with instantaneous correlation $\rho, d W_{1}(t) d W_{2}(t)=\rho$, with $x_{0}, y_{0}, \beta_{x}, \beta_{x}, \mu_{x}, \mu_{y}, \sigma_{x}, \sigma_{y}$ positive constants. Daily data on French 3-month and 10-year maturity bond yields from January 2010 to December 2019 are used to calibrate the model. Table 2 provides ML estimates of the short rate and the long-rate stochastic processes.

Table 2: Parameter estimates of the 2-factor Vasicek model

\begin{tabular}{rccc}
\hline Parameter & $\hat{\mu}_{i}$ & $\hat{\beta}_{i}$ & $\hat{\sigma}_{i}$ \\
\hline Short rate $x_{t}$ & 0.001139806 & 0.385488994 & 0.004164698 \\
Long rate $y_{t}$ & 0.041437594 & 0.143457215 & 0.007023459 \\
\hline
\end{tabular}

Source: author's preparation. Note: We estimate that $\hat{\rho}=0.8838434$.

We assume stock market prices $S_{t}$ follow a standard geometric Brownian motion diffusion process:

$$
\frac{d S_{t}}{S_{t}}=\mu d t+\sigma d W_{t},
$$

where $W_{t}$ is a standard Wiener process with respect to the physical probability measure; $\mu$ and $\sigma$ denote, respectively, the instantaneous stock price drift and volatility. The dynamics of stock prices are calibrated to the CAC-40 index stock market data over the same period considering the index values adjusted for dividends and splits. The ML parameter estimates are $(\hat{\mu}, \hat{\sigma})=(0.05853774 ; 0.19325248)$. CPI inflation values are simulated using a random walk with drift model. The PLLA contract is priced using a longevity option decomposition approach considering 10000 simulations of mortality and financial market risk factors [16-17].2

\subsection{Stochastic mortality modeling}

To forecast age-specific mortality rates, we use a member of the GAPC family of stochastic mortality models, the single population standard age-period Lee-Carter model under a Poisson setting [12].3 Let $D_{x, t}$ denote the number of deaths recorded at age $x$ during calendar year $t$ from the centrally exposed-to-risk $E_{x, t}^{c}$. The GAPC model links a response variable $\left(\mu_{x, t}\right)$ to a linear predictor $\eta_{x, t}$, capturing the systematic effects of age $x$ and time $t$

$$
\eta_{x, t}=\alpha_{x}+\beta_{x}^{(1)} \kappa_{t}^{(1)}
$$

\footnotetext{
${ }^{2}$ Without loss of generality, insurers default risk is not considered [25-26, 31].

${ }^{3}$ An alternative approach is to use a Bayesian Model Ensemble (model combinations) of stochastic mortality models [2, 6, 22, $27,35]$ or continuous-time affine-jump diffusion models [17,30].
} 
where $\exp \left(\alpha_{x}\right)$ denotes the general shape of the mortality schedule across age, $\beta_{x}^{(1)} \kappa_{t}^{(1)}$ is an age-period term describing the mortality trends, with the time index $\kappa_{t}^{(1)}$ capturing the general mortality trend and $\beta_{x}^{(1)}$ tempering its effect across ages. The framework assumes $D_{x, t}$ follows a Poisson distribution $D_{x, t} \sim \mathcal{P}\left(\mu_{x, t} E_{x, t}^{c}\right) \quad$ with $\mathbb{E}\left(D_{x, t} / E_{x, t}^{c}\right)=\mu_{x, t}$. The specification is complemented with a set of identifiability constraints to ensure unique parameter estimates. We first calibrate the model to French total population data from 1950 to 2018 and ages in the range 50-95. Mortality data is obtained from the Human Mortality Database (2020). To forecast and simulate mortality rates, we then assume the age vectors $\alpha_{x}$ and $\beta_{x}^{(1)}$ remain constant over time and model the period index $\kappa_{t}^{(1)}$ using a univariate time series $\operatorname{ARIMA}(p, d, q)$ model.

\section{RESULTS}

Figure 1 reports the average annual nominal consumption level for each drawdown strategy tested in this study. Figure 2 reports individual point forecasts of consumption trajectories, along with the $95 \%$ prediction intervals.

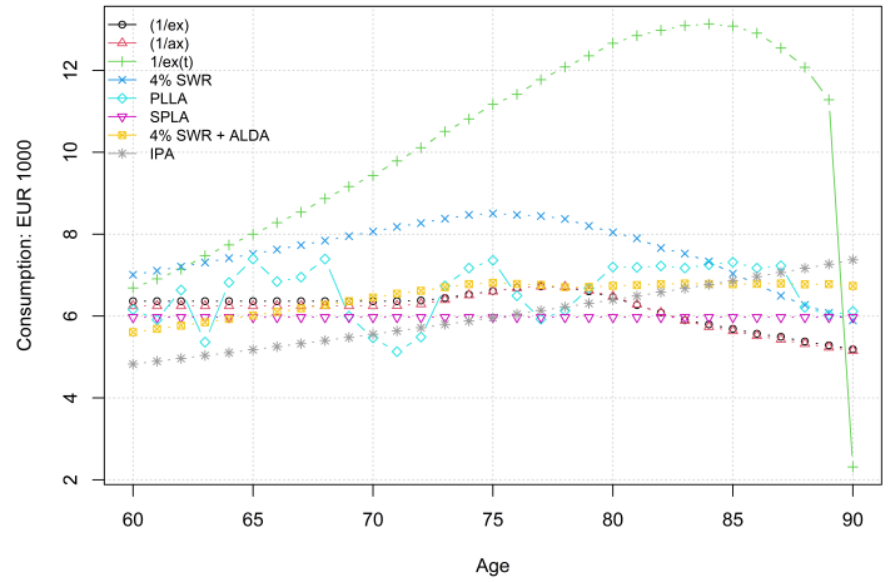

Figure 1: Average annual consumption path by drawdown strategy; Note: Average values computed over the 10000 simulations.

Figure 3 exhibits the corresponding average retirement wealth dynamics by drawdown strategy. The simulation results show that the self-managed variable drawdown rule based on a dynamic assessment of the remaining cohort life expectancy at old age and the classical 4\% SWR rule delivers the highest nominal (and inflation-adjusted) average consumption levels in the age range 60-90 years old but are both financially unsustainable and do not provide longevity insurance. The self-managed fixed drawdown rules $\left(1 / e_{x_{0}, t_{0}}\right.$ and $\left.1 / a_{x_{0}, t_{0}}\right)$ generate similar and relatively low consumption levels throughout retirement, in many years below those provided by annuitization strategies, with individuals likely to pass away with too much unconsumed wealth. Among the full annuitization strategies, the highest nominal and inflation-adjusted average consumption (and welfare) values are generated by the PLLA contract, followed by the IPA structure. Non-insurance-based decumulation strategies are riskier than insurance-based and mixed strategies exhibiting higher nominal (and real) income volatility. The income and consumption volatility of PLLA benefits is naturally higher than that of fixed annuities with annuity payments 
variability bounded at $20 \%$ of the initial benefit, but consumption levels are higher. The hybrid strategy combining the 4\% SWR rule and a 15-year deferred ALDA annuity generates increasing consumption levels at retirement while providing minimal longevity insurance. Full annuitization strategies discard the bequest motive.

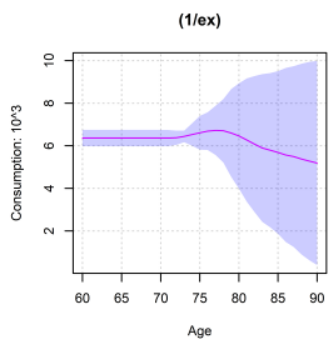

PLLA

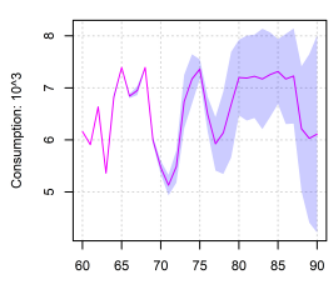

Age

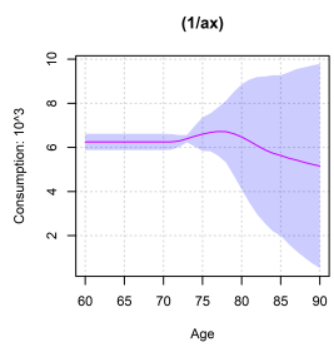

SPLA

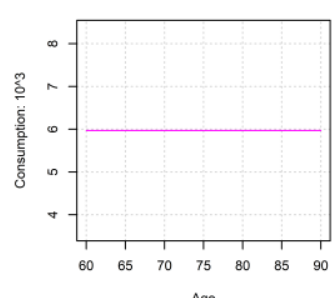

Age

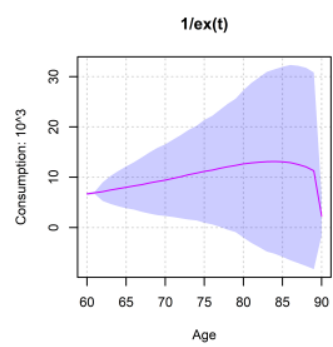

$4 \%$ SWR + ALDA

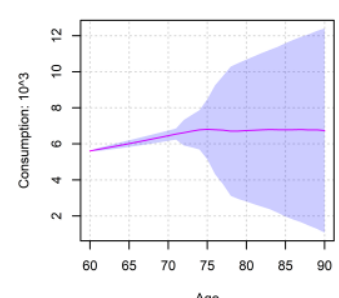

Age

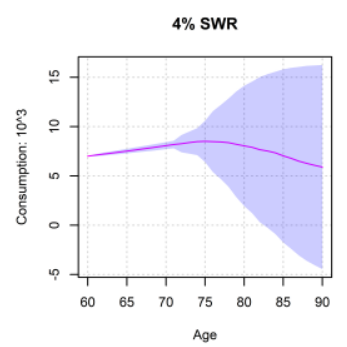

IPA

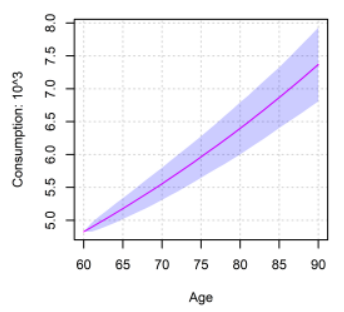

Figure 2: Point forecast of annual consumption levels per draw down strategy, along with the $95 \%$ prediction intervals.

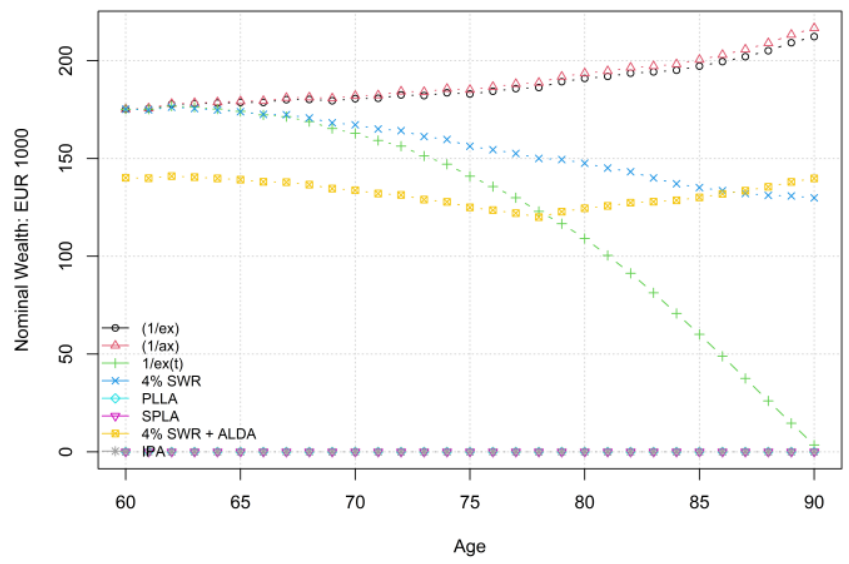

Figure 3: Average retirement wealth dynamics by drawdown strategy; Note: Average values computed over 10000 simulations.

Table 3 summarizes the average welfare analysis metrics for each drawdown strategy analyzed in this study over the 10000 simulations and age range 60-90 years old. The results show that the highest utility score values $\left(S_{0}\right)$ in the age range 60-90 are obtained by the $4 \%$ SWR, $1 / e_{x_{0}+k, t_{0}+k}$ and PLLA drawdown strategies, respectively. However, the performance of the $4 \%$ SWR and $1 / e_{x_{0}+k, t_{0}+k}$ self-managed variable decumulation strategies significantly deteriorate if we extend the analysis to older ages $(x \geq 90)$ since their prescribed consumption path 
is financially not sustainable and individuals are likely to outlive their retirement savings. Moreover, the income volatility is significant for these strategies meaning that the preference for higher income and consumption at early retirement ages may encourage high risk-taking which runs against the preference for a smooth income stream at retirement. On the contrary, the performance of the PLLA is interesting despite prescribing no residual benefit (bequest) which acts often as a reserve pool for many expected and surprise life events related to aging such as healthcare, dependency expenses, traveling, and family. Indeed, Table 3 values do not fully capture the benefits of longevity insurance provided by the PLLA (and all annuitization strategies) since the analysis is focused on the 6090 age range. The mixed strategy 4\% SWR + ALDA provides an interesting combination between risk exposure, longevity protection, and the bequest motive, generating and increasing income profile with limited ruin probability. The inflation-protected annuity is an interesting solution for conservative individuals with no bequest motive. The welfare gap results over the age range 60-90 show, e.g., that the self-managed fixed drawdown strategy based on life expectancy estimates at retirement age requires an additional initial retirement savings amount of 23.330 euros to produce the same expected utility of the $4 \%$ SWR rule.

Table 3: Welfare analysis metrics

\begin{tabular}{|l|l|c|c|c|c|c|c|c|}
\hline$\#$ & Drawdown strategy & $c_{t}$ & $c_{t}$ volat. & $W_{t}$ & $S_{0}$ & $S_{\mathrm{c}}$ & $C E C_{0}$ & $G_{0}$ \\
\hline 1 & $1 / e_{x_{0}, t_{0}}$ & 6.20 & 0.59 & 187.49 & 6.33 & 6.19 & 3.01 & NA \\
2 & $1 / a_{x_{0}, t_{0}}$ & 6.14 & 0.60 & 189.54 & 6.28 & 6.14 & 2.99 & -0.85 \\
3 & $1 / e_{x_{0}+k, t_{0}+k}$ & 10.23 & 3.94 & 122.50 & 6.54 & 6.39 & 3.11 & 4.11 \\
4 & $4 \%$ SWR & 7.58 & 2.12 & 155.52 & 7.52 & 7.36 & 3.58 & 23.33 \\
5 & PLLA & 6.59 & 0.74 & 0.00 & 6.44 & 6.30 & 3.06 & 2.18 \\
6 & SPLA & 5.97 & 0.00 & 0.00 & 6.10 & 5.97 & 2.91 & -4.31 \\
7 & $4 \%$ SWR + ALDA & 6.24 & 1.07 & 124.07 & 5.71 & 5.59 & 2.72 & -11.93 \\
8 & IPA & 6.01 & 0.77 & 0.00 & 5.66 & 5.53 & 2.69 & -12.96 \\
\hline
\end{tabular}

Source: Author's elaboration; Notes: Average values in thousands of euros over 10000 simulations and age range 60-90 years old. Welfare gap $G_{0}$ values estimated comparing all strategies against the self-managed fixed drawdown rule based on cohort life expectancy estimated at time $t_{0}$.

\section{CONCLUSION}

In this paper, we adopted a simulation design to empirically investigate the individual welfare generated from alternative annuitization and self-managed fixed, variable and hybrid drawdown strategies using French data. Our results show that self-managed variable decumulation strategies based on a dynamic assessment of the remaining cohort life expectancy at old age and the classical 4\% SWR rule generate higher income at the expense of high-risk taking, high-income volatility, no longevity insurance, and high ruin probability. Individuals often prefer selfmanaged drawdown strategies relative to annuitization to preserve the control of assets and better cope with unexpected uninsurable expenses, but they fail to provide income smoothness and longevity insurance. Among the full annuitization strategies, those involving longevity-linked life annuities and hybrid solutions provide higher expected lifetime utility but leave no room for bequest motives. The results suggest buying an inflation-protected annuity is an interesting solution for conservative individuals with no bequest motive. Further research is needed to assess the sensitivity of our results to the length of the investment horizon considering lifetime strategies, and to assess the robustness of decumulation strategies to changes in the asset allocation strategy and risk profiles, considering for lifecycle, reverse lifecycle, and hybrid approaches. Simulation designs considering alternative utility 
function designs may be required to evaluate the importance of specific consumption constraints (e.g., healthcare expenses, long-term care costs) in the individual welfare generated from alternative drawdown designs.

\section{ACKNOWLEDGMENTS}

Najat El Mekkaoui acknowledges support by Groupama Gan Vie, Groupama Asset Management and Deloitte. Jorge M. Bravo acknowledges financial support by Portuguese national funds through FCT under the project UIDB/04152/2020 - Centro de Investigação em Gestão de Informação (MagIC).

\section{REFERENCES}

[1] OECD (2019). Pensions at a Glance 2019: OECD and G20 Indicators. OECD Publishing, Paris.

[2] Bravo, J. M., Ayuso, M., Holzmann, R., \& Palmer, E. (2021). Addressing the Life Expectancy Gap in Pension Policy. Insurance: Mathematics and Economics, 99, 200-221. https://doi.org/10.1016/i.insmatheco.2021.03.025

[3] Ayuso, M., Bravo, J. M. \& Holzmann, R. (2021). Getting Life Expectancy Estimates Right for Pension Policy: Period versus Cohort Approach. Journal of Pension Economics and Finance, 20(2), 212-231. https://doi.org/10.1017/S1474747220000050

[4] MacDonald, B-J., Jones, B., Morrison, R., Brown, R. \& Hardy, M. (2013). Research and Reality: A Literature Review on Drawing Down Retirement Financial Savings, North American Actuarial Journal, 17(3), 181-215.

[5] Bravo, J. M. (2019). Funding for longer lives: Retirement wallet and risk-sharing annuities. Ekonomiaz, 96(2), $268-291$.

[6] Bravo, J. M., Ayuso, M. (2021). Forecasting the retirement age: A Bayesian Model Ensemble Approach. In: Rocha Á., Adeli H., Dzemyda G., Moreira F., Ramalho Correia A.M. (eds) Trends and Applications in Information Systems and Technologies, pp 123-135. WorldCIST 2021. Advances in Intelligent Systems and Computing, vol 1365. Springer, Cham. https://doi.org/10.1007/978-3-030-72657-7 12

[7] Abdelkhalek, T., Arestoff, F., El Mekkaoui De Freitas, N., Mage, S. (2020). A microeconometric analysis of household savings determinants in Morocco. African Review of Money Finance and Banking, 7-27.

[8] El Mekkaoui, N., Briard, K. Duc, C. Legendre, B., \& Mage, S. (2011). Career Interruptions: how do they impact pension rights? The Geneva Papers on Risk and Insurance - Issues and Practice 36, 440-457.

[9] El Mekkaoui, N. \& Martins, J. (2014). Health, pension benefits and longevity: How they affect household savings? The Journal of the Economics of Ageing, 3, 21-28.

[10] Bravo, J. M., \& Herce, J. A. (2020). Career breaks, Broken pensions? Long-run effects of early and late-career unemployment spells on pension entitlements. Journal of Pension Economics and Finance 1-27. https://doi.org/10.1017/S1474747220000189

[11] Bravo, J. M. (2016). Taxation of Pensions in Portugal: A Semi-Dual Income Tax System. CESifo DICE Report, 14 (1), $14-23$.

[12] Brouhns, N., Denuit, M., \& Vermunt, J. (2002). A Poisson Log-Bilinear Regression approach to the construction of projected life tables. Insurance: Mathematics and Economics, 31: 373-393.

[13] Vasicek, O. (1977). An Equilibrium Characterization of the Term structure. Journal of Financial Economics, 5, $177-88$.

[14] Bengen, W. P. Determining Withdrawal Rates Using Historical Data. Journal of Financial Planning, 1994, 17 (3): $172-180$.

[15] Pfau, W. D. Making Sense Out of Variable Spending Strategies for Retirees. Journal of Financial Planning, 2015,28 (10), 42-51.

[16] Bravo, J. M., \& El Mekkaoui de Freitas, N. (2018). Valuation of longevity-linked life annuities. Insurance: Mathematics and Economics, 78, 212229.

[17] Bravo, J. M., \& Nunes, J. P. V. (2021). Pricing Longevity Derivatives via Fourier Transforms. Insurance: Mathematics and Economics, $96,81-97$.

[18] Bell, D., Liu, E. and Shao, A. Member's Default Utility Function for Default Fund Design Version 1 (\MDUF v1"), Working Paper, Sydney, 2017.

[19] Human Mortality Database (2020). University of California, Berkeley (USA), and Max Planck Institute for Demographic Research (Germany).

[20] Bravo, J. M., \& Silva, C. M. (2006). Immunization Using a Stochastic Process Independent Multifactor Model: The Portuguese Experience. Journal of Banking and Finance, 30 (1), 133-156.

[21] Valdez, E., Piggott, J. \& Wang, L. (2006). Demand and Adverse Selection in a Pooled Annuity Fund, Insurance: Mathematics and Economics, 39(2), 251-266.

[22] Bravo, J. M., Ayuso, M. (2020). Previsões de mortalidade e de esperança de vida mediante combinação Bayesiana de modelos: Uma aplicação à população portuguesa. RISTI - Revista Iberica de Sistemas e Tecnologias de Informacao E40, 128-144. DOI: 10.17013/risti.40.128-145.

[23] Milevsky, M. A. \& Salisbury, T. S. (2015). Optimal retirement income tontines. Insurance: Mathematics and Economics, 64, 91-105.

[24] Milevsky, M. and Huang, H. (2011). Spending retirement on Plan et Vulcan: The impact of longevity risk aversion on optimal withdrawal rates. Financial Analysts Journal, 67, 45-58.

[25] Chamboko, R., \& Bravo, J. M. (2016). On the modelling of prognosis from delinquency to normal performance on retail consumer loans. Risk Management, 18(4), 264-287.

[26] Chamboko, R, Bravo, J. M. (2020). A Multi-State Approach to Modelling Intermediate Events and Multiple Mortgage Loan Outcomes. Risks, 8, 64.

[27] Ayuso, M., Bravo, J. M., Holzmann, R. \& Palmer, E. (2021). Automatic indexation of the pension age to life expectancy: When policy design 
matters. Risks, 9(5), 96. https://doi.org/10.3390/risks9050096

[28] Bravo, J. M. (2020). Longevity-Linked Life Annuities: A Bayesian Model Ensemble Pricing Approach. CAPSI 2020 Proceedings, Atas da Conferencia da Associação Portuguesa de Sistemas de Informação, 29. https://aisel.aisnet.org/capsi2020/29.

[29] Simões, C., Oliveira, L., \& Bravo, J. M. (2021). Immunization Strategies for Funding Multiple Inflation-Linked Retirement Income Benefits. Risks 9(4): 60; https://doi.org/10.3390/risks9040060

[30] Bravo, J. M. (2021). Pricing Survivor Bonds with Affine-Jump Diffusion Stochastic Mortality Models. ICEEG 2021: 2021 The 5th International Conference on E-Commerce, E-Business and E-Government. Association for Computing Machinery (ACM), New York, NY, USA, 91-96. https://doi.org/10.1145/3466029.3466037

[31] Ashofteh, A., \& Bravo, J. M. (2021). A Conservative Approach for Online Credit Scoring. Expert Systems With Applications, $176(15), 114835$. https://doi.org/10.1016/i.eswa.2021.114835.

[32] Ashofteh, A. \& Bravo, J. M. (2021). Spark Code: A Novel Conservative Approach for Online Credit Scoring [Source Code]. https://doi.org/10.24433/C0.1963899. v1

[33] Chamboko, R. \& Bravo, J. M. (2019). Frailty correlated default on retail consumer loans in developing markets. International Journal of Applied Decision Sciences, 12(3), 257-270.

[34] Chamboko, R. \& Bravo, J. M. (2019). Modelling and forecasting recurrent recovery events on consumer loans. International Journal of Applied Decision Sciences, 12(3), 271-287.

[35] Ashofteh, A. \& Bravo, J. M. (2021). Life Table Forecasting in COVID-19 Times: An Ensemble Learning Approach. 2021 16th Iberian Conference on Information Systems and Technologies (CISTI), 2021, pp. 1-6, DOI: 10.23919/CISTI52073.2021.9476583. https://ieeexplore.ieee.org/document/9476583

[36] Bravo, J. M. (2021). Pricing Participating Longevity-Linked Life Annuities: A Bayesian Model Ensemble approach. European Actuarial Journal. https://doi.org/10.1007/s13385-021-00279-w 